\title{
Perbedaan Karakteristik, Jenis Persalinan, Luaran Ibu dan Bayi Antara Preterm Dini dan Lanjut
}

\author{
Mirza Sulanda Panji Putra, Johannes C Mose, Zulvayanti, Edwin Armawan \\ Departemen Obstetri dan Ginekologi Fakultas Kedokteran Universitas Padjadjaran/ \\ RSUP Hasan Sadikin Bandung \\ Korepondensi : Mirza Sulanda Panji Putra,Email: mirza_sulanda@yahoo.com
}

\begin{abstract}
Abstrak
Tujuan: Kelahiran preterm dibagi menjadi dini dan lanjut. Kelahiran preterm memiliki angka, mortalitas dan morbiditas yang cukup tinggi. Data mengenai preterm dini dan lanjut di RSHS masih minim sehingga penelitian ini perlu untuk dilakukan.

Metode: Penelitian ini merupakan penelitian analitik komparatif secara cross-sectional untuk menganalisis apakah terdapat perbedaan signifikan mengenai karakteristik ibu (riwayat paritas, pendidikan, pekerjaan, riwayat menikah) dengan persalinan preterm dini dan lanjut. Data berjumlah 125 pasien diambil melalui rekam medis dari Januari 2018 sampai Desember 2019.

Hasil: Preterm lanjut ditemukan lebih banyak pada kelompok paritas 1 (60,6\%), kelompok pendidikan SMP (40,8\%), kelompok pekerjaan ibu rumah tangga $(66,7 \%)$, dan kelompok status pernikahan menikah (43,9\%). Preterm dini ditemukan lebih banyak pada kelompok paritas 3 (53,7\%), kelompok pendidikan SD (73,7\%), kelompok pekerjaan ibu rumah tanga $(58,2 \%)$, dan status pernikahan menikah $(56,1 \%)$. Pada kelompok karakteristik tidak terdapat perbedaan bermakna antara preterm dini dan lanjut. Terdapat perbedaan bermakna antara preterm dini dan lanjut untuk variabel luaran ibu $(p=0,028)$ dan luaran bayi $(p=0,001)$.

Kesimpulan: Terdapat perbedaan yang bermakna pada preterm dini dan lanjut untuk variabel luaran ibu (jenis persalinan) dan variabel luaran bayi (ruang rawat bayi).
\end{abstract}

Kata kunci: Karakteristik, jenis persalinan, luaran, kelahiran preterm.

\section{Differences Between Characteristics, Types of Delivery, Mother and Baby Outcome Between Early and Late Preterm}

\begin{abstract}
Objective: Preterm birth divided into early and late. Preterm birth has a fairly high incidence, mortality and morbidity rate. Risk factors of preterm birth are multifactorial. Data related to preterm at RSHS is very minimal so this research needs to be done.

Method: This study is a comparative analytic study with cross-sectional approach to analyze the significant differences in characteristics of mothers (parity history, education, occupation, marriage history) preterm labor. Data from 125 patients is collected through medical records from January 2018 to December 2019.

Result: Late preterm was found more in parity 1 group (60.6\%), junior high school group (40.8\%), housewives (66.7\%), and marital status group (43.9\%). Early preterm was found more in parity 3 group (53.7\%), elementary school group (73.7\%), housewives (58.2\%), and marital status (56.1\%). In characteristic group there were no significant differences between early and late preterm. There were significant differences between early and late preterm variables for maternal outcomes $(p=0.028)$ and infant outcomes $p=0.001)$.

Conclusion: There are significant differences between early and late preterm for maternal outcome variables (type of delivery) and infant outcome (level 1 and level III ward).
\end{abstract}

Key word: Characteristics, type of delivery, outcome, preterm birth. 


\section{Pendahuluan}

Kelahiran preterm merupakan kelahiran yang terjadi pada usia kehamilan kurang dari 37 minggu. Kelahiran preterm dibagi menjadi dua berdasarkan usia kehamilannya, yaitu kelahiran preterm dini dan lanjut. Kelahiran preterm dini terjadi pada usia kehamilan kurang dari 34 minggu, sedangkan kelahiran preterm lanjut terjadi pada usia kehamilan antara 34 sampai 36 minggu 6 hari. Tiga perempat kelahiran preterm diketahui merupakan kelahiran preterm lanjut. ${ }^{1}$ Indonesia menempati urutan kelima dengan jumlah kelahiran preterm terbanyak, yakni diperkirakan sejumlah 527.672 kelahiran. ${ }^{2}$

Kelahiran preterm terjadi akibat dari banyak faktor. ${ }^{1,3}$ Faktor sosial yang diketahui berperan adalah kemiskinan, pekerjaan, pendidikan, status pernikahan, dan lingkungan tempat tinggal. ${ }^{1,4}$ Penelitian sebelumnya yang dilakukan di Rumah Sakit Umum Pusat dr Hasan Sadikin menyatakan bahwa faktor-faktor yang berperan dalam kejadian kelahiran preterm diantaranya adalah usia ibu yang terlalu muda, kunjungan antenatal care kurang dari empat kali, riwayat kelahiran preterm sebelumnya, anemia, hipertensi, dan perdarahan antepartum. ${ }^{5}$

Persalinan pada kelahiran preterm dapat dilakukan secara pervaginam maupun perabdominam.

Pada kelahiran preterm spontan dengan presentasi kepala, didapatkan bahwa persalinan secara seksio sesarea berhubungan dengan morbiditas yang lebih tinggi pada ibu dibandingkan persalinan pervaginam. ${ }^{6}$

Persalinan secara seksio sesarea pada kelahiran preterm dini diketahui tidak menjamin bayi terhindar dari luaran yang buruk, seperti kematian, perdarahan intraventrikel, kejang, gangguan pernapasan, dan perdarahan subdural. ${ }^{1}$

Bayi yang lahir preterm diketahui berisiko tinggi mengalami beberapa penyakit akibat imaturitas sistem organnya. ${ }^{1,7,8}$
Komplikasi yang sering terjadi terkait kelahiran preterm diantaranya adalah gangguan pernafasan, perdarahan intraventrikel, sepsis, dan gangguan perkembangan syaraf., ${ }^{1,9}$

Bayi yang terlahir secara preterm memiliki komplikasi yang berhubungan dengan lama perawatan dan ruang perawatan intensif.

Kelahiran preterm dini dan lanjut memiliki angka kejadian yang cukup tinggi dan menyebabkan tingginya mortalitas dan morbiditas pada bayi, sehingga kejadian kelahiran preterm harus dicegah.

Pemecahan masalah kelahiran preterm dapat dengan dilakukan dengan cara mengenali faktor resiko, pemberian edukasi baik pada saat sebelum menikah maupun pada saat kondisi hamil.

Dengan pengenalan sedini mungkin akan bahaya kelahiran preterm diharapkan angka kejadian kelahiran preterm dapat ditekan. Data penelitian mengenai perbedaan faktor risiko, jenis persalinan, dan luaran pada kelahiran preterm dini dan lanjut masih minim, sehingga penelitian ini perlu untuk dilakukan.

\section{Metode}

Populasi sasaran pada penelitian ini adalah perempuan dengan persalinan kurang bulan di RSHS. Populasi terjangkau adalah perempuan dengan persalinan kurang bulan yaitu lebih dari 32 minggu dan sampai 36 minggu dari hari pertama haid terakhir pada siklus menstruasi 28 hari yang datang ke bagian Obstetri RSHS yang memenuhi kriteria inklusi dan tidak termasuk kriteria eksklusi.

Kriteria inklusi dari penelitian ini adalah ibu hamil yang melahirkan di RSHS dari Januari 2018 sampai Desember 2019, bayi lahir tunggal, usia kehamilan pada saat bayi lahir adalah preterm dini $(32-33$ minggu $)$ atau preterm lanjut (34-36 minggu). Kriteria 
eksklusi dari penelitian ini adalah bayi yang lahir dengan kelainan kongenital mayor serta bayi yang lahir dengan penyerta iatrogenik (ketuban pecah dini, preeklamsi, perdarahan antepartum).

Penelitian ini merupakan penelitian analitik komparatif dengan pendekatan crosssectional untuk menganalisis apakah terdapat perbedaan yang signifikan dalam beberapa faktor risiko (paritas, pendidikan, pekerjaan, dan riwayat pernikahan) yang mengalami persalinan preterm.

Data diambil melalui rekam medis dari Januari 2018 sampai Desember 2019.

Grup dibagi menjadi dua, yaitu ibu yang melahirkan bayi preterm dini yaitu usia kehamilan $<34$ minggu dan ibu yang melahirkan bayi preterm lanjut yaitu $>34$ minggu.

Analisis statistik sesuai tujuan penelitian dan hipotesis yaitu untuk mengetahui perbedaan dan korelasi antara data-data sosial serta faktor-faktor risiko preterm pada parturien preterm dan gravida preterm.. Analisis statistik untuk data kategorik diuji dengan uji Chi-Square dengan alternatif uji Exact Fisher.

Kemudian untuk data numerik, sebelum dilakukan uji statistika, data numerik tersebut dilakukan uji normalitas dengan menggunakan uji Shapiro-Wilk karena jumlah data kurang dari 50.

Uji ini digunakan untuk menguji apakah data berdistribusi normal atau berdistribusi tidak normal.

Uji statistika untuk membandingkan karakteristik dua kelompok penelitian digunakan uji $\mathrm{t}$ tidak berpasangan jika data berdistribusi normal atau uji Mann-Whitney sebagai alternatif nya jika data tidak berdistribusi normal.

Adapun kriteria kemaknaan yang ditentukan berdasarkan nilai $\mathrm{p} \leq 0,05$ artinya signifikan atau bermakna secara statistika, dan $p>0,05$ tidak signifikan atau tidak bermakna secara statistik. Data yang diperoleh dicatat dalam formulir khusus kemudian diolah melalui program SPSS versi 25 for Windows.

\section{Hasil}

Tabel 1 menjelaskan karakteristik pasien yang diteliti. Berdasarkan kelompok paritas, preterm lanjut ditemukan lebih banyak pada kelompok paritas P1 yaitu sebesar 20 $(60,6 \%)$ sedangkan preterm dini ditemukan lebih banyak pada kelompok paritas $\mathrm{P} 3$ yaitu sebesar $22(53,7 \%)$.

Berdasarkan kelompok pendidikan, preterm lanjut ditemukan lebih banyak pada kelompok pendidikan SMP yaitu sebesar 20 $(40,8 \%)$ sedangkan preterm dini ditemukan lebih banyak pada kelompok pendidikan SMP yaitu sebesar $29(59,2 \%)$.

Berdasarkan kelompok pekerjaan, preterm lanjut ditemukan lebih banyak pada kelompok pekerjaan ibu rumah tangga yaitu sebesar $33(41,8 \%)$ sedangkan preterm dini ditemukan lebih banyak pada kelompok pekerjaan ibu rumah tangga yaitu sebesar 46 $(58,2 \%)$.

Berdasarkan status pernikahaan, preterm dini ditemukan lebih banyak pada status menikah yaitu sebesar $64(56,1 \%)$.

Pada kelompok karakteristik ibu (paritas, pendidikan, pekerjaan, status pernikahan) tidak ditemukan perbedaan yang bermakna antara kehamilan preterm dini dan lanjut.

Tabel 2 menjelaskan hubungan antara preterm dengan luaran ibu dan luaran bayi.

Perbedaan proporsi dengan menggunakan uji statistik chi-square atau Uji Fisher menunjukkan bahwa terdapat perbedaan proporsi yang bermakna yaitu jenis persalinan seksio sesarea dan jenis persalinan pervaginam dengan nilai $\mathrm{p}$ sebesar 0,028 . Selain itu, terdapat perbedaan proporsi yang bermakna yaitu Level I dan Level III dengan nilai $p$ sebesar $<0,001$. 
Tabel 1 Karakteristik dasar subjek penelitian

\begin{tabular}{|c|c|c|c|}
\hline \multirow[b]{2}{*}{ Karateristik } & \multicolumn{2}{|c|}{ Preterm } & \multirow[b]{2}{*}{ Nilai p } \\
\hline & $\begin{array}{c}\text { Dini } \\
(n, \%)\end{array}$ & $\begin{array}{l}\text { Lanjut } \\
(\mathbf{n}, \%)\end{array}$ & \\
\hline \multicolumn{4}{|l|}{ Paritas } \\
\hline - $\quad$ P1 (33) & $13(39,4 \%)$ & $20(60,6 \%)$ & $0,249^{\mathrm{cs}}$ \\
\hline - $\quad$ P2 (32) & $15(46,9 \%)$ & $17(53,1 \%)$ & $0,883^{\mathrm{cs}}$ \\
\hline - $\quad$ P3 (41) & $22(53,7 \%)$ & $19(46,3 \%)$ & $0,376^{\mathrm{cs}}$ \\
\hline - $\quad$ P4 (19) & $10(52,6 \%)$ & $9(47,4 \%)$ & $0,661^{\mathrm{cs}}$ \\
\hline \multicolumn{4}{|l|}{ Pendidikan } \\
\hline - $\quad \mathrm{SD}(38)$ & $28(73,7 \%)$ & $10(26,3 \%)$ & $0,051^{\mathrm{cs}}$ \\
\hline - $\quad \operatorname{SMP}(49)$ & $29(59,2 \%)$ & $20(40,8 \%)$ & $0,766^{\mathrm{cs}}$ \\
\hline - $\quad$ SMA (26) & $15(57,7 \%)$ & $11(42,3 \%)$ & $0,715^{\mathrm{cs}}$ \\
\hline - $\quad \mathrm{S} 1(12)$ & $4(33,3 \%)$ & $8(66,7 \%)$ & $0,06^{\mathrm{f}}$ \\
\hline \multicolumn{4}{|l|}{ Pekerjaan } \\
\hline $\begin{array}{l}\text { - Ibu Rumah Tangga } \\
\text { (IRT) (79) }\end{array}$ & $46(58,2 \%)$ & $33(41,8 \%)$ & $0,959^{\mathrm{cs}}$ \\
\hline - $\quad$ Buruh (23) & $14(60,9 \%)$ & $9(39,1 \%)$ & $0,79^{\mathrm{cs}}$ \\
\hline - $\quad$ Pedagang (17) & $11(64,7 \%)$ & $6(35,3 \%)$ & $0,57^{\mathrm{cs}}$ \\
\hline - Wiraswasta (6) & $2(33,3 \%)$ & $4(66,7 \%)$ & $0,233^{\mathrm{f}}$ \\
\hline \multicolumn{4}{|l|}{ Pernikahan } \\
\hline - $\quad$ Menikah (114) & $64(56,1 \%)$ & $50(43,9)$ & $0,352^{\mathrm{f}}$ \\
\hline - $\quad$ Janda (11) & $8(72,7 \%)$ & $3(27,3 \%)$ & \\
\hline
\end{tabular}

Tabel 2. Hubungan antara luaran ibu dengan status preterm

\begin{tabular}{|c|c|c|c|c|}
\hline \multirow{2}{*}{ Variabel } & \multicolumn{2}{|c|}{ Luaran Ibu } & \multirow{2}{*}{\multicolumn{2}{|c|}{$\begin{array}{c}\text { Nilai } \\
\mathbf{p}\end{array}$}} \\
\hline & $\begin{array}{c}\text { SC } \\
(n=51)\end{array}$ & $\begin{array}{c}\text { Spontan } \\
(\mathrm{n}=74)\end{array}$ & & \\
\hline \multicolumn{5}{|l|}{ Preterm } \\
\hline - Preterm Dini & $32(53,3 \%)$ & $28(46,7 \%)$ & \multirow{2}{*}{\multicolumn{2}{|c|}{0,028}} \\
\hline - Preterm Lanjut & $47(72,3 \%)$ & $18(27,7 \%)$ & & \\
\hline \multirow{2}{*}{ Variabel } & \multicolumn{3}{|c|}{ Luaran Bayi } & \multirow{2}{*}{ Nilai P } \\
\hline & $\begin{array}{c}\text { Level I } \\
(n=61)\end{array}$ & $\begin{array}{c}\text { Level II } \\
(n=44)\end{array}$ & $\begin{array}{c}\text { Level III } \\
(n=20)\end{array}$ & \\
\hline \multicolumn{5}{|l|}{ Preterm } \\
\hline - Dini & $22(33,8 \%)$ & $27(41,5 \%)$ & $16(24.6 \%)$ & $<0,001$ \\
\hline - Lanjut & $39(65 \%)$ & $17(28,3 \%)$ & $4(6,7 \%)$ & \\
\hline
\end{tabular}




\section{Pembahasan}

Kelahiran preterm berhubungan dengan banyak faktor yang mungkin saling berhubungan. Penelitian ini meneliti tentang hubungan karakteristik ibu dengan kejadian kelahiran preterm dini danlanjut. Karakteristik ibu yang diteliti adalah jumlah paritas, tingkat pendidikan, pekerjaan, dan status pernikahan. Secara umum, tidak didapatkan perbedaan yang bermakna secara statistik antara keempat faktor tersebut pada kelahiran preterm dini dan lanjut. Hal ini berbeda dengan hasil penelitian yang dilakukan pada negara bagian Italia (Umbria) yang menyatakan bahwa faktor sosioekonomik individual sangat berpengaruh terhadap kejadian kelahiran preterm. ${ }^{10}$

Hasil penelitian terkait jumlah paritas pada penelitian ini menyatakan bahwa kelahiran preterm dini lebih banyak terjadi pada $\mathrm{P} 3$ dan $\mathrm{P} 4$, sedangkan kelahiran preterm lanjut lebih banyak terjadi pada P1 dan P2. Tidak terdapat perbedaan proporsi yang bermakna secara statistik antara preterm dini dan lanjut berdasarkan kelompok paritas. Studi oleh Ashlety dkk menunjukkan bahwa baik wanita multipara usia muda maupun wanita nullipara usia lanjut memilik risiko kejadian preterm yang lebih tinggi. ${ }^{11}$ Hasil ini sejalan dengan studi yang dilakukan oleh Ben dkk yang menunjukkan bahwa wanita usia lanjut merupakan faktor risiko independen pada preterm sebelum usia 37 minggu baik pada wanita nullipara maupun multipara. ${ }^{12}$

Kelahiran preterm dini ditemukan lebih banyak pada tingkat pendidikan SD, SMP, dan SMA, sedangkan kelahiran preterm lanjut didapatkan lebih banyak pada tingkat pendidikan S1. Namun, tidak terdapat perbedaan proporsi yang bermakna secara statistik antara preterm dini dan lanjut berdasarkan kelompok tingkat pendidikan. Hasil studi ini berbeda dengan studi yang dilakukan oleh Eve Overton dkk yang menunjukkan bahwa tingkat pendidikan ibu yang rendah memiliki hubungan yang bermakna dengan peningkatan risiko kejadian preterm. ${ }^{13}$ Studi lain yang dilakukan oleh Laura dkk juga menunjukkan bahwa wanita dengan tingkat pendidikan yang rendah memiliki 2 kali peningkatan risiko preterm. Studi lain yang dilakukan di Quebec, Kanada menunjukkan bahwa angka premturitas menurun seiring dengan bertambahnya tingkat pendidikan. ${ }^{14}$ Studi lain menunjukkan bahwa preterm sebesar 92\% lebih tinggi pada wanita dengan edukasi yang rendah dibandingkan wanita dengan edukasi yang lebih tinggi. ${ }^{15}$

Kelahiran preterm dini ditemukan lebih banyak pada kelompok pekerjaan ibu rumah tangga, buruh, dan pedagang, sedangkan preterm lanjut ditemukan lebih banyak pada kelompok pekerjaan wiraswasta. Tidak terdapat perbedaan proporsi yang bermakna secara statistik antara preterm dini dan lanjut berdasarkan kelompok pekerjaan. Penelitian di negara bagian Italia menyatakan bahwa kelahiran preterm lebih banyak terjadi pada kelompok pekerjaan dengan penghasilan yang lebih rendah. ${ }^{10}$

Kelahiran preterm dini ditemukan lebih banyak pada ibu dengan status janda daripada dengan status menikah. Hal ini sejalan dengan beberapa penelitian lain yang juga menyatakan bahwa ibu dengan status janda merupakan salah satu faktor risiko independen terjadinya kelahiran preterm..$^{10,16,17}$ Salah satu penyebabnya diduga karena keterbatasan akses menuju layanan kesehatan untuk melakukan pemeriksaan antenatal pada ibu dengan status janda. ${ }^{10}$ Namun, tidak terdapat perbedaan proporsi yang bermakna secara statistik antara preterm dini dan lanjut berdasarkan status pernikahan.

Hasil penelitian ini menunjukkan bahwa terdapat perbedaan proporsi yang bermakna berdasarkan preterm untuk variabel luaran ibu yaitu jenis persalinan seksio sesarea dan jenis persalinan pervaginam spontan dengan nilai $p$ sebesar 0,028 . Studi yang dilakukan Laura dkk 
menunjukkan bahwa jenis persalinan seksio sesarea memiliki proporsi yang lebih tinggi terjadinya preterm. ${ }^{18}$ Bayi yang dilahirkan dengan persalinan seksio sesarea memiliki angka 15\% lebih tinggi kemungkinan terjadi preterm. Studi di Pelotas, Rio Grande do Sul yang melakukan studi kohort menunjukkan bahwa angka kejadian seksio sesarea yang meningkat dari $28 \%$ menjadi $45 \%$ berhubungan dengan peningkatan kejadian preterm sebesar $6,3 \%$ menjadi $14,7 \% .{ }^{18}$ Perlu diperhatikan bahwa dalam menganalisis preterm yang berhubungan dengan persalinan seksio sesarea, terdapat banyak faktor yang menjadi indikasi persalinan seksio sesarea yang berkaitan dengan risiko preterm. ${ }^{18}$

Hasil studi ini juga menunjukkan bahwa terdapat perbedaan proporsi yang bermakna berdasarkan preterm untuk variabel luaran bayi yaitu Level I dan Level III dengan nilai $\mathrm{p}$ sebesar $<0,001$. Hal ini sejalan dengan penelitian lain. Preterm lanjut diketahui memiliki masalah kesehatan yang lebih sedikit dan ringan dibandingkan preterm dini. ${ }^{19}$ Penelitian lain menyebutkan bahwa morbiditas dan mortalitas bayi menurun dengan bertambahnya usia kehamilan sampai cukup bulan kemudian meningkat kembali ketika memasuki post-term. ${ }^{20}$ Morbiditas dan disabilitas akibat kelahiran preterm tidak hanya terjadi pada masa bayi, tetapi juga bisa terjadi pada usia lanjut seperti cerebral palsy, performa sekolah yang buruk, pendidikan berkebutuhan khusus, dan asma. ${ }^{20}$

Dari penelitian ini dapat disimpulkan tidak terdapat perbedaan yang bermakna berdasarkan karakteristik ibu pada kehamilan preterm dini dan lanjut. Terdapat perbedaan yang bermakna berdasarkan luaran ibu yaitu persalinan seksio sesarea dan jenis persalinan pervaginam pada kehamilan preterm dini dan lanjut. Terdapat perbedaan yang bermakna berdasakan luaran bayi yaitu ruang perawatan level 1, 2 dan 3 pada kehamilan preterm dini dan lanjut.

\section{Daftar Pustaka}

1. Cunningham FG, Leveno KJ, Bloom SL, Spong CY, Dashe JS, Hoffman BL, et al. Preterm Birth. Williams Obstetrics. 25 ${ }^{\text {th }}$ ed. New York: McGraw-Hill Education; 2018. p. 2049.

2. Chawanpaiboon S, Vogel JP, Moller A-B, Lumbiganon P, Petzold M, Hogan $\mathrm{D}$, et al. Global, regional, and national estimates of levels of preterm birth in 2014: a systematic review and modelling analysis. The Lancet Global Health. 2019;7(1):e37-e46.

3. Garn JV, Nagulesapillai T, Metcalfe A, Tough S, Kramer MR. International comparison of common risk factors of preterm birth between the US and Canada, using PRAMS and MES (20052006). Maternal and child health journal. 2015;19(4):811-8.

4. Delnord M, Blondel B, Zeitlin J. What contributes to disparities in the preterm birth rate in European countries? Current opinion in obstetrics \& gynecology. 2015;27(2):133.

5. Hidayat ZZ, Ajiz EA, Krisnadi SR. Risk factors associated with preterm birth at hasan sadikin general hospital in 2015. Open Journal of Obstetrics and Gynecology. 2016;6(13):798.

6. MottetN, Riethmuller D. Mode of delivery in spontaneous preterm birth. Journal de gynecologie, obstetrique et biologie de la reproduction. 2016;45(10):1434-45.

7. Organization WH. WHO recommendations on interventions to improve preterm birth outcomes. 2015.

8. Liu L, Oza S, Hogan D, Chu Y, Perin $\mathrm{J}$, Zhu J, et al. Global, regional, and national causes of under-5 mortality in 2000-15: an updated systematic analysis with implications for the Sustainable Development Goals. The Lancet. 2016;388(10063):3027-35.

9. Glass HC, Costarino AT, Stayer SA, 
Brett C, Cladis F, Davis PJ. Outcomes for extremely preterm infants. Anesthesia and analgesia. 2015;120(6):1337.

10. Chiavarini M, Bartolucci F, Gili A, Pieroni L, Minelli L. Effects of individual and social factors on preterm birth and low birth weight: empirical evidence from regional data in Italy. International Journal of Public Health. 2012;57(2):261-8.

11. Simhan HN, Berghella V, Iams JD. Preterm labor and birth. Creasy and restnik's maternal-fetal medicine: principle and practice. 72014.

12. Buhimschi CS, Norman JE. Pathogenesis of spontaneous preterm birth. Creasy and restnik's maternal-fetal medicine: principle and practice. 72014. p. 599-623.

13. Mercer BM, Goldenberg RL, Moawad AH, Meis PJ, Iams JD, Das AF, et al. The preterm prediction study: effect of gestational age and cause of preterm birth on subsequent obstetric outcome. National Institute of Child Health and Human Development Maternal-Fetal Medicine Units Network. Am J Obstet Gynecol. 1999;181(5 Pt 1):1216-21.

14. Mercer BM, Goldenberg RL, Das A, Moawad AH, Iams JD, Meis PJ, et al. The preterm prediction study: a clinical risk assessment system. Am J Obstet Gynecol. 1996;174(6):1885-93; discussion 93-5.

15. Ananth CV, Getahun D, Peltier MR, Salihu HM, Vintzileos AM. Recurrence of spontaneous versus medically indicated preterm birth. Am J Obstet Gynecol. 2006;195(3):643-50.

16. Beeckman K, Van de Putte S, Putman $\mathrm{K}$, Louckx F. Predictive social factors in relation to preterm birth in a metropolitan region. 2009;88(7):787-92.

17. Iyoke C, Lawani L, Ezugwu E, Ilo K, Ilechukwu G, Asinobi I. Maternal risk factors for singleton preterm births and survival at the University of Nigeria Teaching Hospital, Enugu, Nigeria. Nigerian journal of clinical practice.
2015;18(6):744-50.

18. Winkvist A, Mogren I, Hogberg U. Familial patterns in birth characteristics: impact on individual and population risks. International journal of epidemiology. 1998;27(2):248-54.

19. Morgan JC, Boyle EM. The late preterm infant. Paediatrics and Child Health. 2018;28(1):13-7.

20. Shapiro-Mendoza CK, Lackritz EM, editors. Epidemiology of late and moderate preterm birth. Seminars in Fetal and Neonatal Medicine; 2012: Elsevier. 